\title{
Two cases of disseminated superficial actinic porokeratosis (DSAP) and treatment literature review
}

\author{
Elena Thomaidou', Marian Katz², Vera Leibovici ${ }^{1}$
}

\author{
${ }^{1}$ Department of Dermatology, Hadassah- Hebrew University Medical Center, Jerusalem, Israel, ${ }^{2}$ Meuhedet Sick Fund, \\ Jerusalem, Israel
}

Corresponding author: Dr. Vera Leibovici, E-mail: Rveralibo@hadassah.org.il

\begin{abstract}
Background: Disseminated superficial actinic porokeratosis (DSAP) is characterized by asymptomatic multiple papules with annular keratotic rim distributed symmetrically on the sun-exposed areas. Many approaches have been proposed in the past for treating DSAP, but the therapy is still a challenge for every physician, mostly because of the frequent relapses of the disease and the multiplicity of the skin lesions. Material and Methods: Two case reports were reported emphasizing the challenges of treatment approach. Therefore, a systemic English literature review was conducted searching Medline database using PubMed Central and Ovid software as search interface to collect evidence based on the various treatment modalities for DSAP. Results: The initial search yielded 146 articles, but only the relevant case reports, case series and studies relating to the treatment of DSAP have been described and summarized in a table. For each different therapy the efficacy of each treatment, side effects, cost-effectiveness and authors' recommendations were reported. Conclusion: Several factors need to be considered prior to physicians' decision of the most appropriate treatment for each patient like age, the extent of body surface area involvement, patients' medical history and social situation, the available resources, the side effects and cost- effectiveness of each treatment. However, 1 the exact value of each treatment is difficult to determine owing to the lack of controlled studies evaluating their efficacy. Due to few incidences of squamous cell carcinoma, patients need to be followed up and monitored closely for any early detection of recurrence or possible onset of malignancies.
\end{abstract}

Key words: Porokeratosis; Keratinizing disorders; Lasers; Photodynamic therapy

\section{INTRODUCTION}

Disseminated superficial actinic porokeratosis (DSAP) was first described by Chernosky and Freeman [1]. Clinically, DSAP is characterized by asymptomatic multiple papules with annular keratotic rim distributed symmetrically on the sun-exposed areas, and facial involvement is a rare presentation ${ }^{1}$. Malignant degeneration has been described in $7 \%$ to $11 \%$ of porokeratoses cases, with squamous cell carcinoma being the most common [2-4]. Histological hallmark is the cornoid lamella, which is formed by clonal hyperproliferation of atypical keratinocytes [3]. Underlying the cornoid lamella, the granular layer is thinned or absent and keratinocytes are oedematous with spongiosis, and dermal lymphocytic infiltrate may also be evident [5]. Dermoscopy examination demonstrate single or double "white track" structure at the margin corresponding to the cornoid lamella, and the red dots, globules, and lines are enlarged capillary vessels that can be observed because the epithelium is atrophic [6].

Xia and colleagues using a genomewide search in a large Chinese family, identified a locus at chromosome 12q23.2-24. 1 responsible for disseminated superficial actinic porokeratosis [7]. Therefore, DSAP is an inherited dermatologic disorder with lesions appearing in genetically predisposed individuals after adequate exposure to ultraviolet radiation or immunosuppression in the third and fourth decades of life [8].

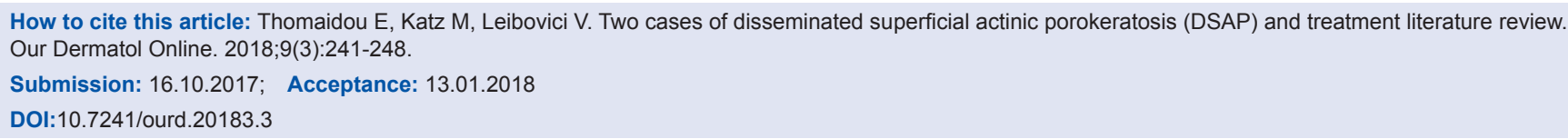


A variety of approaches have been proposed to treat DSAP, but the therapy is still a challenge for every physician, mostly because of the multiplicity of the skin lesions and the frequent relapses of the disease [9]. Herein, we present two case reports with a great dilemma in treatment approach, following by an update literature review.

\section{CASES}

Case 1: An eighteen four-year-old man presented in our clinic with 6-month history of bilateral symmetrical erythematous skin lesions on the lower and upper extremities. The skin eruptions were associated with photosensitivity and moderate pruritus. The patient had a background medical history of hypercholesteremia, hypertension, ischemic heart disease, congestive heart disease, diabetes mellitus type 2, non-alcoholic fatty liver, chronic renal failure and glaucoma.

On examination bilateral erythematous scaly papules with annular configuration, well -demarcated borders and central atrophy were seen on the shins, thighs and forearm (Figs. la and lb). Dermoscopy examination revealed a white like track structures at the periphery of the lesion with a mild hyperpigmentation in the inner side and with some red globules, and lines at the periphery (Fig. 2). On histological examination cornoid lamella was found in the stratum corneum with focal loss of granular layer, prominent lichenoid, superficial perivascular lymphocytic infiltrate and background elastosis (Figs. 3a and 3b).

Case 2: An eighteen one-year-old man with background history of diabetes mellitus type 2, bronchiectasis, asthma, ischemic heart disease, aortic stenosis and mitral insufficiency was examined in our clinic due to 3-year history of annular non-pruritic lesions on the shins. In the past, he was treated with steroid intralesional injections without any improvement.

On examination, there were multiple annular erythematous lesions with central clearing and elevated borders on the shins (Figs. lc and ld). Histological examination revealed cornoid lamella with absence of the granular layer. The intervening epidermis between the cornoid lamellae was thin and in the upper dermis there were perivascular mononuclear and lichenoid cells.

According to the clinical and histological presentation, both of our patients were diagnosed with disseminated superficial actinic porokeratosis. Their clinical presentation, risk of malignancy, medical history and their social situation was considered for choosing the most appropriate treatment for the patient.

Prior to the study, patient gave written consent to the examination and biopsy after having been informed about the procedure.

\section{METHOD}

A systemic English literature review was conducted in June 2017 searching Medline database using PubMed Central and Ovid software as search interface to collect
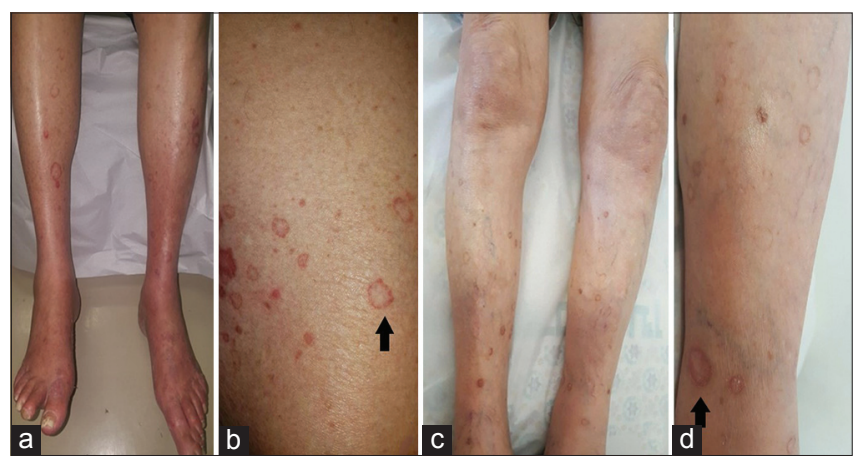

Figure 1: (a-d) Bilateral erythematous scaly papules with annular configuration on the shins, thighs and forearm with well - demarcated borders and central atrophy.

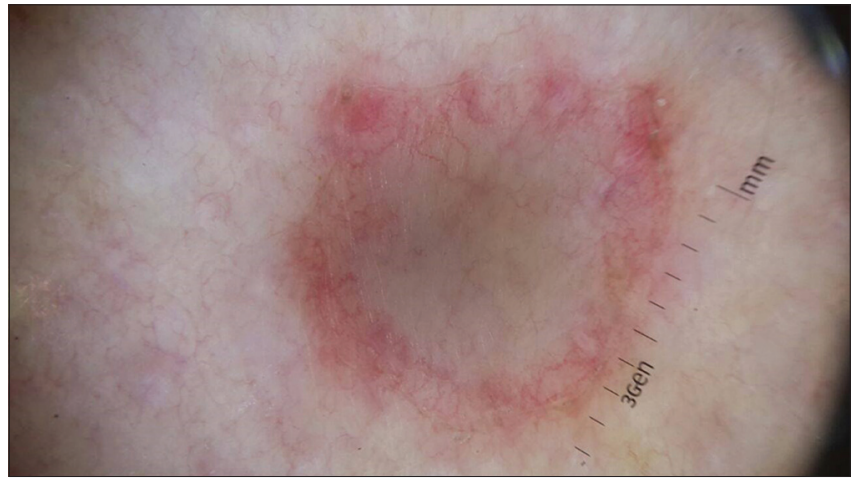

Figure 2: A "white track" structures can be identified at the periphery of the lesion with a brownish pigmentation in the inner side and with some red globules, and lines at the periphery.

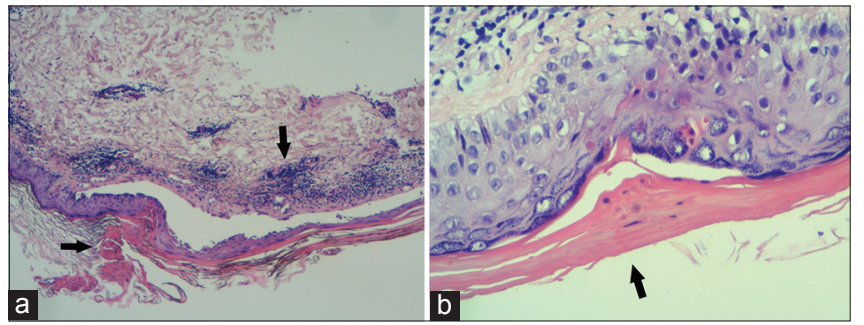

Figure 3: $(a$ and $b)$ Cornoid lamella was found in the stratum corneum with focal loss of granular layer, prominent lichenoid, superficial perivascular lymphocytic infiltrate and background elastosis. (Hematoxylin and Eosin, 40x, 400x). 


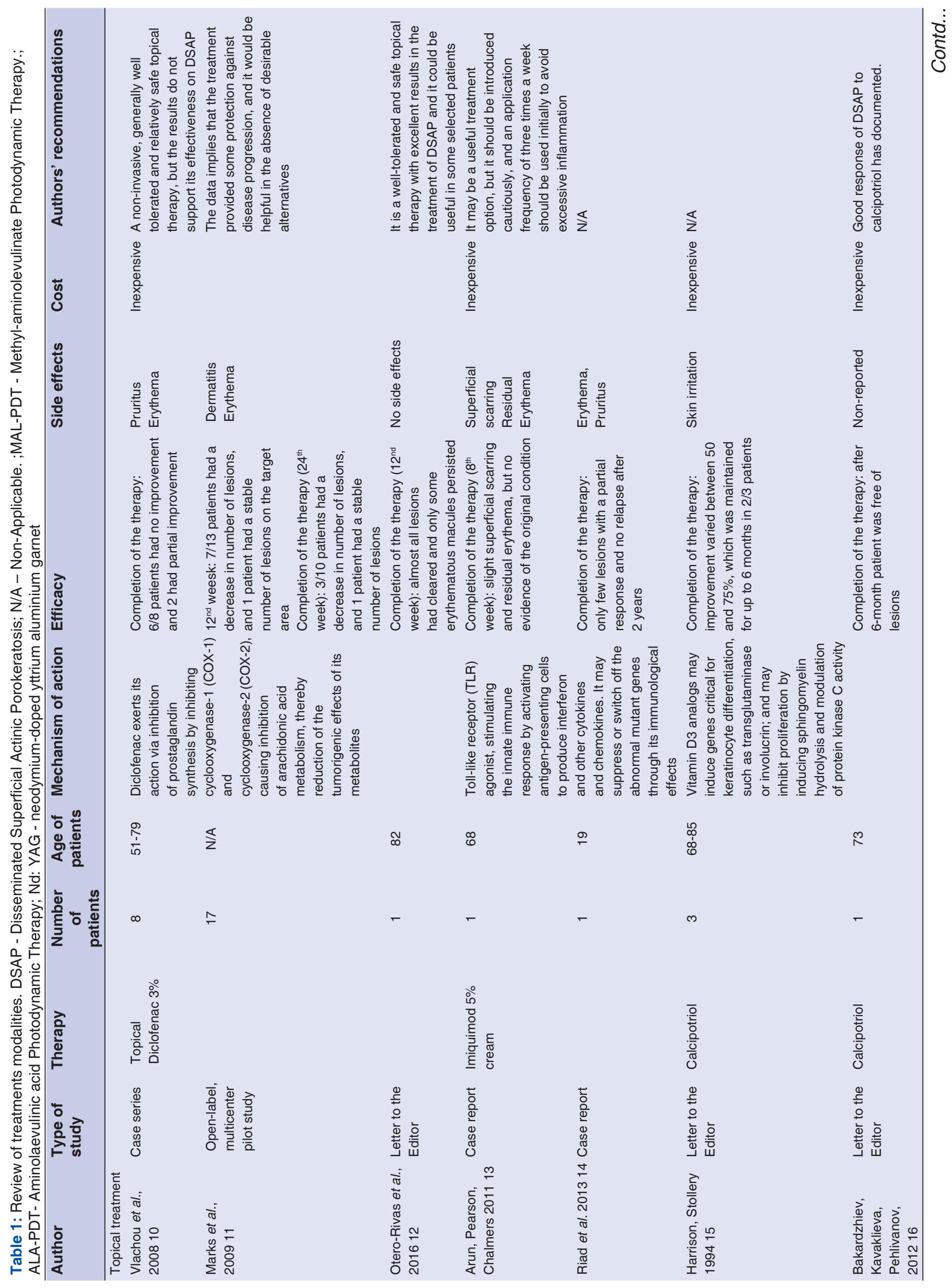




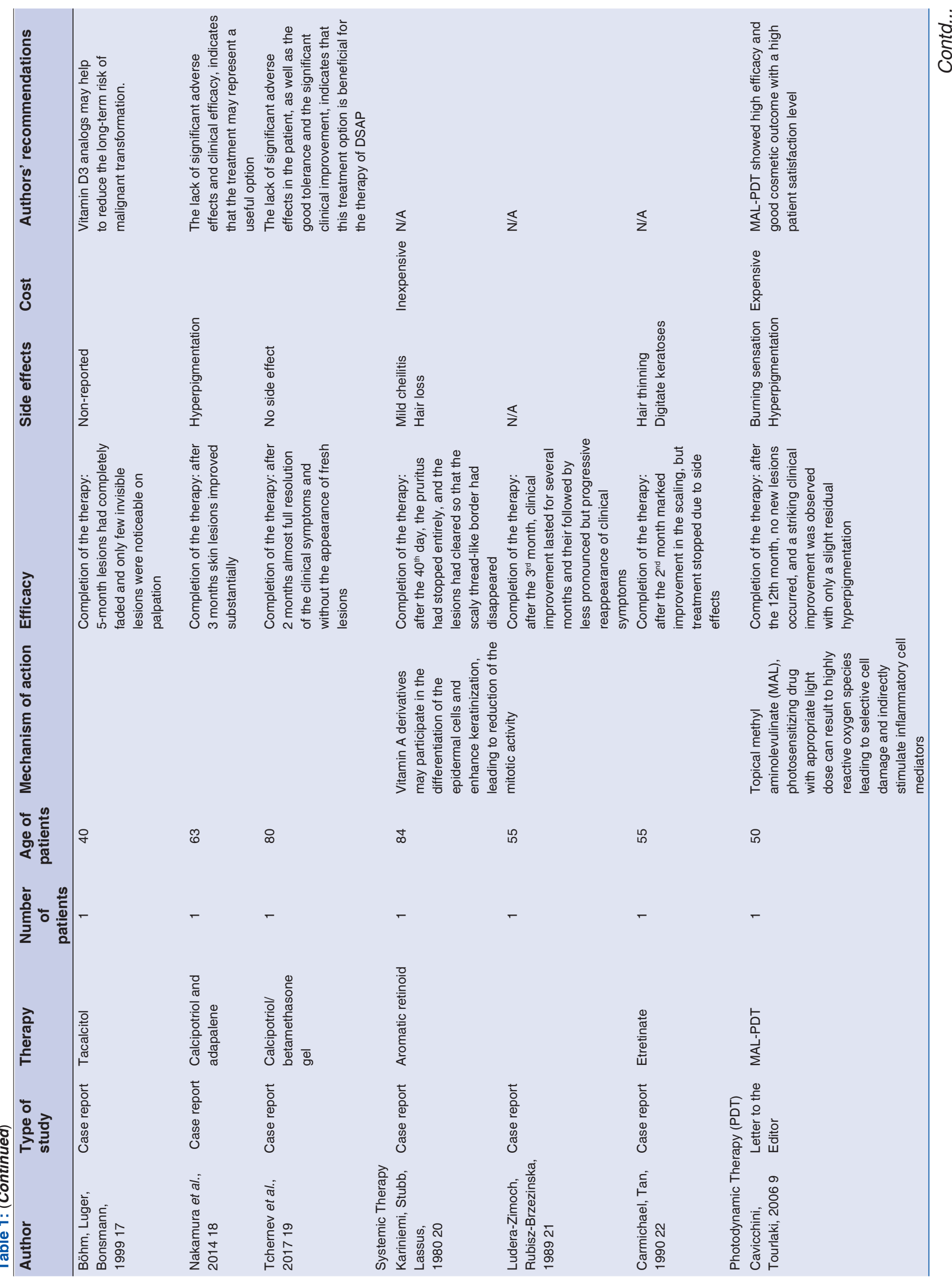




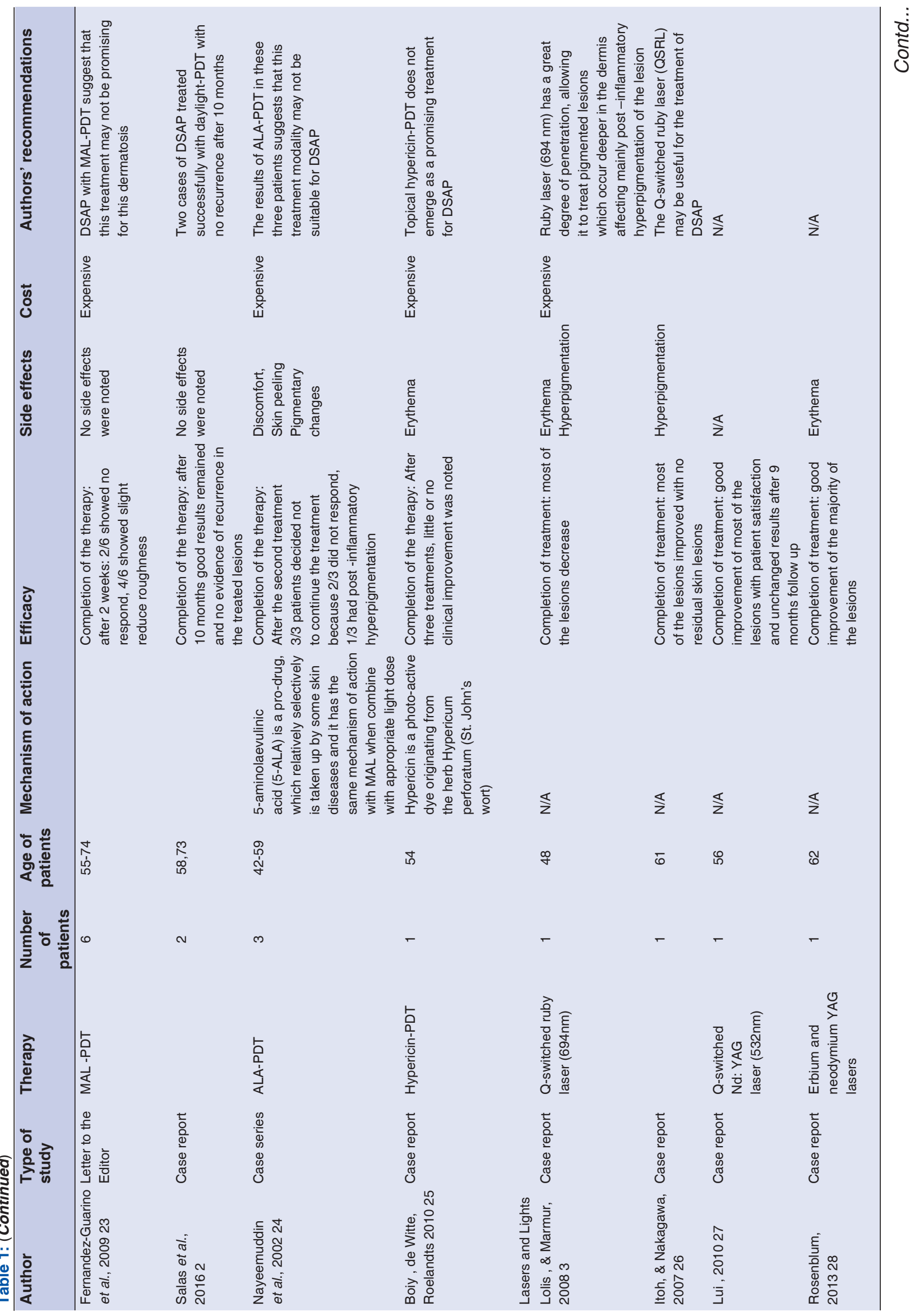


www.odermatol.com

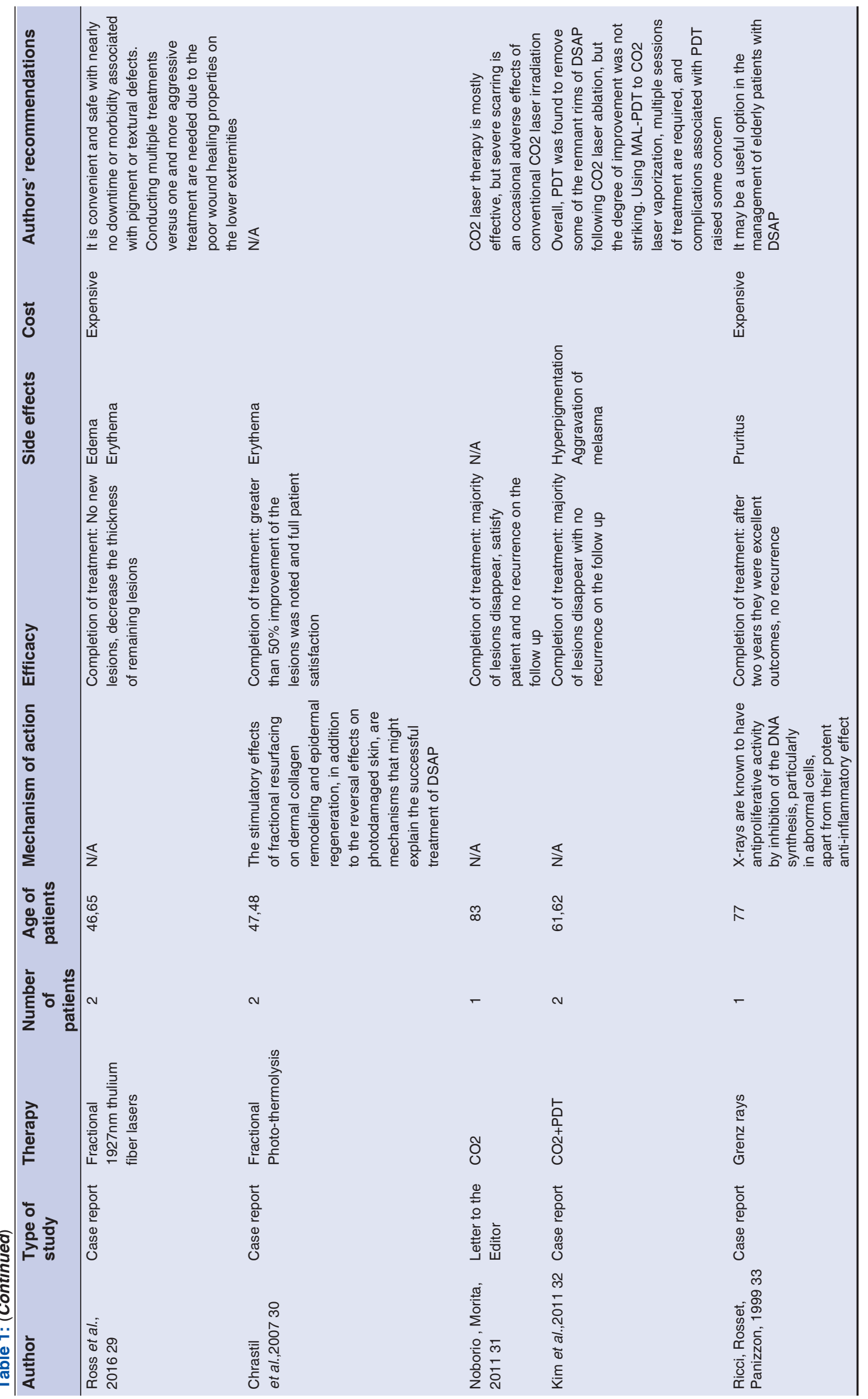


evidence based on the various treatment modalities for DSAP. In addition, studies that have been commonly cited in the literature and review articles were included as citation search engine to identify subsequent publications, which were relevant for the literature review. The following medical terms and text world were used: "Disseminated superficial actinic porokeratosis", "porokeratosis", "laser", "photodynamic therapy", "diclofenac", "calcipotriol", "imiquimod", "retinoid", "photodynamic therapy", "lasers". The keywords were combined using multiple combinations. Articles that did not mention treatment approaches, which were not published in English or were not available, have not been included for the purposes of this literature review. Any discrepancies about data evaluation of the selected articles were resolved after discussion between the authors.

\section{RESULTS}

The initial search yielded 146 articles, but only the relevant case reports, case series and studies relating to the treatment of DSAP have been described below and summarized in Table 1. For each different therapy the efficacy of each treatment, side effects, cost effectiveness and authors' recommendations were reported.

\section{DISCUSSION}

Traditional topical treatment approaches include topical treatments like diclofenac [10-12], imiquimod [13-14] and calcipotriol [15-19]. Oral retinoids [20-22] and cryotherapy [15] were used in the past with no any satisfied results. Newer treatment of photodynamic therapy (PDT) [2,9,23-25] and lasers [3,26-32] have been introduced in the recent years with some desirables results. A literature review was conducted five years ago assessing the level of evidence for some therapeutic modalities. However, still the exact value of each treatment is difficult to determine owing to the lack of controlled studies evaluating their efficacy [5].

Several factors need to be considered for choosing the most appropriate treatment for each patient, like the age, the extent of body surface area involvement, patients' medical history and their social situation, the available resources in dermatology departments, the side effects and cost effectiveness of each treatment approaches. Systemic treatment might not be an option if patients have complicated medical background and take multiple medications, due to possible interactions of retinoids with their regular medications. Expensive treatment like different types of lasers can be discussed with the patients but usually are not considered due to the high cost and lack of experienced centres. PDT therapy showed poor outcome in several studies (e.g. six out of nine patients had none or minimal response with MAL- PDT, all patients had no response with ALA-PDT and Hypericin-PDT), thus it is not recommended frequently $[2,9,23-35]$.

Following a thorough discussion among physicians in our clinic, both patients started on topical treatment with calcipotriol/betamethasone gel with partial resolution. Patients are under follow up and they will be monitored closely for any possible onset of malignancies. In conclusion, there are several options available for treating DSAP, but always the best approach should be tailored to every patient. There is still a great need for further controlled studies with a greater sample size to draw conclusions on the effects of these novel treatments for DSAP.

\section{Statement of Human and Animal Rights}

All procedures followed were in accordance with the ethical standards of the responsible committee on human experimentation (institutional and national) and with the Helsinki Declaration of 1975 , as revised in 2008 .

\section{Statement of Informed Consent}

Informed consent was obtained from all patients for being included in the study.

\section{REFERENCES}

1. Chernosky ME, Freeman RG. Disseminated superficial actinic porokeratosis (DSAP). Arch Dermatol. 1967;96:611-24.

2. Salas T, Hernandez-Gil J, Lopez A, Dorado M, Ruiz J, Garcia E, et al. Two cases of disseminated superficial actinic porokeratosis treated with daylight-mediated photodynamic therapy. Dermatol Ther. 2016;29:484-5.

3. Lolis MS, Marmur ES. Treatment of disseminated superficial actinic porokeratosis (DSAP) with the Q-switched ruby laser. J Cosmet Laser Ther. 2008;10:124-7.

4. Maubec E, Duvillard P, Margulis A, Bachollet B, Degois G, Avril MF. Common skin cancers in porokeratosis. BrJ Dermatol. 2005;152:1389-91.

5. Skupsky H, Skupsky J, Goldenberg G. Disseminated superficial actinic porokeratosis: a treatment review. J Dermatolog Treat. 2012;23:52-6.

6. Zaballos P, Puig S, Malvehy J. Dermoscopy of disseminated superficial actinic porokeratosis. Arch of Dermatol. 2004;140:1410. 
7. Xia JH, Yang YF, Deng H, Tang BS, Tang DS, He YG, et al. Identification of a locus for disseminated superficial actinic porokeratosis at chromosome 12q23.2-24.1. J Invest Dermatol. 2000;114:1071-4.

8. Aird GA, Sitenga JL, Nguyen AH, Vaudreuil, A, Huerter, CJ. Light and laser treatment modalities for disseminated superficial actinic porokeratosis: a systematic review. Lasers Med Sci. 2017;32:945-52.

9. Cavicchini S, Tourlaki A. Successful treatment of disseminated superficial actinic porokeratosis with methyl aminolevulinatephotodynamic therapy. J Dermatolog Treat. 2006;17:190-1.

10. Vlachou C, Kanelleas AI, Martin-Clavijo A, Berth-Jones J. Treatment of disseminated superficial actinic porokeratosis with topical diclofenac gel: a case series. J Eur Acad Dermatol Venereol. 2008;22:1343-5.

11. Marks S, Varma R, Cantrell W, Chen SC, Gold M, Muellenhoff M, et al. Diclofenac sodium 3\% gel as a potential treatment for disseminated superficial actinic porokeratosis. J Eur Acad Dermatol Venereol. 2009;23:42-5.

12. Otero-Rivas MM, Rodriguez-Lojo R, Castineiras-Mato IM, Lueiro-Vilarino M, Juarez-Casado Y, Fernandez-Diaz ML. Successful management of disseminated superficial actinic porokeratosis with diclofenac sodium 3\% gel. Dermatol Ther. 2017;30(3).

13. Arun B, Pearson J, Chalmers R. Disseminated superficial actinic porokeratosis treated effectively with topical imiquimod 5\% cream. Clin Exp Dermatol. 2011;36:509-11.

14. Riad H, Mansour K, Sada HA, Shaika SA, Ansari HA, Mohannadi HA. Disseminated superficial actinic porokeratosis on the face treated with imiquimod 5\% cream. Case Rep Dermatol. 2013;5:283-9.

15. Harrison PV, Stollery N. Disseminated superficial actinic porokeratosis responding to calcipotriol. Clin Exp Dermatol. 1994;19:95.

16. Bakardzhiev I, Kavaklieva S, Pehlivanov G.Successful treatment of disseminated superficial actinic porokeratosis with calcipotriol. Int J Dermatol. 2012;51:1139-42.

17. Bohm M, Luger TA, Bonsmann G. Disseminated superficial actinic porokeratosis: treatment with topical tacalcitol. J Am Acad Dermatol. 1999;40:479-80.

18. Nakamura Y, Yamaguchi M, Nakamura A, Muto M. Calcipotriol and adapalene therapy for disseminated superficial actinic porokeratosis. Indian J Dermatol Venereol Leprol. 2014;80:373-4.

19. Tchernev G, Chokoeva AA, Ivanova B, Mangarov H, Vidolova NG. Disseminated superficial actinic porokeratosis (DSAP): significant improvement after local administration of calcipotriol/ betamethasone gel?”. Wien Med Wochenschr. 2017;167:85-8.

20. Kariniemi AL, Stubb S, Lassus A. Treatment of disseminated superficial actinic porokeratosis with a new aromatic retinoid (Ro 10-9359). Br J Dermatol. 1980;102:213-4.

21. Ludera-Zimoch G, Rubisz-Brzezinska J. [A case of superficial disseminated actinic porokeratosis treated with an aromatic retinoid] Przegl Dermatol.1989;76:54-7.

22. Carmichael AJ, Tan CY. Digitate keratoses--a complication of etretinate used in the treatment of disseminated superficial actinic porokeratosis. Clin Exp Dermatol. 1990;15: 370-1.

23. Fernandez-Guarino M, Harto A, Perez-Garcia B, MartinGonzalez M, Urrutia S, Jaen P. Photodynamic therapy in disseminated superficial actinic porokeratosis. J Eur Acad Dermatol Venereol. 2009;23:176-7.

24. Nayeemuddin FA, Wong M, Yell J, Rhodes LE. Topical photodynamic therapy in disseminated superficial actinic porokeratosis. Clin Exp Dermatol. 2002;27:703-6.

25. Boiy A, de Witte P. A, Roelandts R. Topical treatment of disseminated superficial actinic porokeratosis with hypericinphotodynamic therapy: a case report. Photodiagnosis Photodyn Ther. 2012;7:123-5.

26. Itoh M, Nakagawa H. Successful treatment of disseminated superficial actinic porokeratosis with Q-switched ruby laser. J Dermatol. 2007;34:816-20.

27. Liu HT. Treatment of lichen amyloidosis (LA) and disseminated superficial porokeratosis (DSP) with frequency-doubled Q-switched Nd: YAG laser. Dermatol Surg. 2000:26:958-62.

28. Rosenblum J. Erbium laser for treatment of disseminated superficialactinic porokeratosis. Dermatol Surg. 2013;39:1543-5.

29. Ross NA, Rosenbaum LE, Saedi N, Arndt KA, Dover JS. Disseminated superficial actinic porokeratosis improved with fractional 1927-nm laser treatments. J Cosmet Laser Ther. 2016;18:53-5.

30. Chrastil B, Glaich AS, Goldberg LH, Friedman PM. Fractional photothermolysis: a novel treatment for disseminated superficial actinic porokeratosis. Arch Dermatol. 2007;143:1450-2.

31. Noborio R, Morita A. Split-face trial of CO2 laser-induced ring abrasion and high-dose tacalcitol in the treatment of disseminated superficial actinic porokeratosis. J Dermatol. 2011;39:879-80.

32. Kim HS, Baek JH, Park YM, Kim HO, Lee JY. Photodynamic therapy combined with $\mathrm{CO} 2$ laser vaporization on disseminated superficial actinic porokeratosis: a report of 2 cases on the face. Ann Dermatol. 2011;23:211-3.

33. Ricci C, Rosset A, Panizzon RG. Bullous and pruritic variant of disseminated superficial actinic porokeratosis: successful treatment with Grenz rays. Dermatol. 1999;199:328-31.

Copyright by Elena Thomaidou, et al. This is an open-access article distributed under the terms of the Creative Commons Attribution License, which permits unrestricted use, distribution, and reproduction in any medium, provided the original author and source are credited.

Source of Support: Nil, Conflict of Interest: None declared. 